\title{
Trends and timing of cigarette smoking uptake among US young adults: survival analysis using annual national cohorts from I 976 to 2005
}

\author{
Yvonne M. Terry-McElrath \& Patrick M. O’Malley \\ Institute for Social Research, University of Michigan, Ann Arbor, MI, USA
}

\begin{abstract}
Aims To measure changes over time in cigarette smoking uptake prevalence and timing during young adulthood (ages 19-26 years), and associations between time-invariant/-varying characteristics and uptake prevalence/timing. Design Discrete-time survival modeling of data collected from United States high school seniors (modal age 17/18) enrolled in successive graduating classes from 1976 to 2005 and participating in four follow-up surveys (to modal age 25/26). Setting The longitudinal component of the Monitoring the Future study. Participants A total of 10758 individuals reporting no life-time smoking when first surveyed as high school seniors. Measurements Smoking uptake (any, experimental, occasional and regular); socio-demographic variables; marital, college and work status; time spent socializing. Findings The percentage of young adults moving from non-smoker to experimental smoking [slope estimate 0.11, standard error $(\mathrm{SE})=0.04, P=0.005]$ or occasional smoking (slope estimate $0.17, \mathrm{SE}=0.03, P<0.001$ ) increased significantly across graduating classes; the percentage moving from non-smoker to regular smoker remained stable. All forms of smoking uptake were most likely to occur at age 19/20, but uptake prevalence at older ages increased over time [e.g. cohort year predicting occasional uptake at modal age 25/26 adjusted hazard odds ratio (AHOR) $=1.05, P=0.002$ ] Time-invariant/-varying characteristics had unique associations with the timing of various forms of smoking uptake (e.g. at modal age 21/22, currently attending college increased occasional uptake risk (AHOR $=2.11, P<0.001$ ) but decreased regular uptake risk $(\mathrm{AHOR}=0.69, P=0.026)$. Conclusions $\quad$ Young adult occasional and experimental smoking uptake increased in the United States for non-smoking high school seniors graduating from 1976 to 2005. Smoking uptake for these cohorts remained most likely to occur at age 19/20, but prevalence of uptake at older ages increased.
\end{abstract}

Keywords Cigarette smoking, delayed smoking uptake, discrete-time survival analysis, late smoking uptake, tobacco, young adults.

Correspondence to: Yvonne Terry-McElrath, Institute for Social Research, PO Box 1248, Ann Arbor, MI 48106-1248, USA. E-mail: yterry@umich.edu Submitted 26 November 2014; initial review completed 23 January 2015; final version accepted 5 March 2015

\section{INTRODUCTION}

The World Health Organization (WHO) Framework Convention on Tobacco Control has identified a clear need to prevent tobacco use initiation [1]. Among the majority of cultures world-wide, initiation does not extend past young adulthood [2], a critical period for protecting health identified as ages 18-26 years [3]. National Canadian data on late cigarette smoking uptake indicate that as many as $20 \%$ of ever smokers in 2003 reported trying their first cigarette after age 18 [4]. Among US daily smokers surveyed in 2012, 10\% first tried a cigarette at age 19 or older [5]. A recent systematic review of North American research summarizes evidence indicating a variety of socio- demographic disparities in young adult smoking uptake, and that such uptake may be increasing in recent years while adolescent uptake has been declining [6]. The review authors concluded that additional research is needed examining young adult smoking uptake among a range of populations and uptake levels, including the phenomenon of occasional or social smoking [6].

The current analysis contributes to available research on young adult smoking uptake by utilizing a longitudinal, national cohort-sequential study of US high school seniors followed throughout young adulthood to provide previously unavailable data on the prevalence of various levels of young adult smoking uptake (including social or occasional smoking), the timing of such uptake and if 
time-invariant/-varying characteristics are associated differentially with the risk of moving to various uptake levels. Our specific aims related to young adult smoking uptake prevalence:

(1) Estimate the percentage of young adults reporting no life-time smoking prior to high school graduation that experience any smoking uptake to modal age 25/26;

(2) Estimate the distribution of those progressing from never smoking to (a) experimental smoking only; (b) occasional but not regular smoking; and (c) regular smoking;

(3) Measure trends over time in the prevalence of young adult smoking uptake in various forms; and

(4) Examine socio-demographic associations with the likelihood of different uptake levels.

Our specific aims related to young adult smoking uptake timing:

(1) Identify when (modal age) various levels of smoking uptake are reported;

(2) Measure the degree to which modal age of various forms of uptake has shifted over time; and

(3) Examine socio-demographic associations with the timing of uptake.

\section{METHODS}

\section{Sample and data collection}

The study utilizes data from the Monitoring the Future (MTF) study [7], a national cohort-sequential study. Briefly, a nationally representative sample of approximately 15000 high school seniors from approximately 130 schools is surveyed annually (resulting in sequential cohorts). Self-administered surveys are completed by students, typically during a normal class period. A representative random subsample of 2400 seniors is selected from each annual sample for longitudinal followup; substance users are over-sampled (analyses include weighting to account for sampling procedures). Respondents are divided randomly, with half surveyed in evennumbered years and half in odd-numbered years [7]. Follow-up questionnaires are mailed in the spring with a modest monetary incentive. The current sample was limited to class cohorts from 1976 to 2005 (cohorts with the potential to have participated in four follow-up surveys by the time of 2013 data collection). Overall response rates were: $65 \%$ for first follow-up (1-2 years past high school) and 61,58 and $54 \%$ for follow-ups 2-4, respectively. The sample was limited further to only seniors reporting no life-time smoking and providing adequate data for smoking uptake classification at follow-up 4 (modal age 25/26). Thus, analyses included individuals first surveyed as never-smoking high school seniors in 1976-2005 with modal ages ranging from 18 (high school seniors) to 25/26 (follow-up 4).

\section{Measures}

Young adult smoking uptake

A wide range of smoking initiation measures has been reported in the literature, with recognition of a growing phenomenon of occasional or social smoking where individuals do not self-identify as regular smokers [6]. For this study, smoking status was assessed at each modal age by combining two measures capturing both smoking selfidentity and number of cigarettes smoked. Past 12-month smoking was measured as $1=$ have not smoked at all, $2=$ smoked once or twice, $3=$ smoked occasionally but not regularly, $4=$ smoked regularly but stopped or cut back and $5=$ smoke regularly now. Past 30-day smoking was measured as $1=$ not at all, $2=$ less than one cigarette per day, $3=$ one to five cigarettes per day, $4=$ about half a pack per day, $5=$ about one pack per day, $6=$ about 1.5 packs per day and $7=$ two packs or more per day. A dichotomous time-invariant measure was created identifying respondents who ever versus never reported any smoking uptake by modal age 25/26. A second time-invariant measure identified the highest level of uptake reported: $0=$ never reported uptake, $1=$ uptake to experimental only, $2=$ uptake to occasional but not regular and $3=$ uptake to regular (for specific definitions, see Table 1). Timevarying measures were coded for survival analysis identifying when any uptake occurred and (if so), when the highest specified level of uptake occurred (experimental, occasional or regular).

\section{Time-invariant characteristics}

Time-invariant characteristics identified previously in the literature as being associated with young adult smoking uptake [6] were measured at modal age 18. Gender was coded as male or female. Self-identified race/ethnicity was coded as white, African American, Hispanic or 'other'. College plans were coded as probably/definitely plan to graduate from a 4-year college versus other. Parental education (a proxy for family-of-origin socio-economic status) was a dichotomous measure indicating that at least one parent had graduated from college. Separate dichotomous indicators identified any past 12-month use of alcohol and marijuana. Region (as defined by the US Census) and cohort (year when surveyed as a senior in high school) were coded. To control for the difference in time duration between the high school and first follow-up surveys, given that respondents are divided randomly with half surveyed in even-numbered years and half in odd-numbered years, a dichotomous indicator was coded indicating random assignment to (a) the half-sample surveyed for first follow-up in the year immediately following the senior year (modal age 19) or (b) the half-sample assigned to first follow-up in the second year (modal age 20). The former group were 
Table 1 Time-invariant young adult cigarette smoking uptake classifications.

\begin{tabular}{|c|c|}
\hline Classification name & Definition \\
\hline Any uptake & $\begin{array}{l}\text { Ever report any smoking activity in past } \\
12 \text { months, including once or twice } \\
\text { (inclusive of categories that follow: } \\
\text { experimental, occasional, regular) }\end{array}$ \\
\hline \multicolumn{2}{|l|}{ Level of uptake: } \\
\hline Never reported uptake & $\begin{array}{l}\text { Reported no past } 12 \text {-month or } 30 \text {-day } \\
\text { smoking at all follow-up surveys to } \\
\text { modal age } 25 / 26\end{array}$ \\
\hline $\begin{array}{l}\text { Uptake to experimental } \\
\text { smoking only }\end{array}$ & $\begin{array}{l}\text { Smoked once or twice in the past } 12 \\
\text { months; no smoking in past } 30 \text { days; } \\
\text { never moved to occasional or regular }\end{array}$ \\
\hline $\begin{array}{l}\text { Uptake to occasional but } \\
\text { not regular smoking }\end{array}$ & $\begin{array}{l}\text { Never moved to regular smoking, but } \\
\text { reported one of the following: } \\
\text { (a) Smoked once or twice in the past } 12 \\
\text { months; smoked less than one cigarette } \\
\text { per day in past } 30 \text { days } \\
\text { (b) Smoked occasionally but not } \\
\text { regularly in the past } 12 \text { months; no } \\
\text { smoking in past } 30 \text { days } \\
\text { (c) Smoked occasionally but not } \\
\text { regularly in the past } 12 \text { months; } \\
\text { smoked less than one cigarette per day } \\
\text { in past } 30 \text { days }\end{array}$ \\
\hline $\begin{array}{l}\text { Uptake to regular } \\
\text { smoking }\end{array}$ & $\begin{array}{l}\text { Reported one of the following: } \\
\text { (a) Smoked regularly but stopped or cut } \\
\text { back in past } 12 \text { months } \\
\text { (b) Smoke regularly now } \\
\text { (c) Smoked one or more cigarettes per } \\
\text { day in past } 30 \text { days }\end{array}$ \\
\hline
\end{tabular}

surveyed at modal ages 18, 19, 21, 23 and 25; the latter group were surveyed at modal ages 18, 20, 22, 24 and 26.

\section{Time-varying characteristics}

Time-varying characteristics were measured at each follow-up survey. Three characteristics were chosen based on literature calling for a need to understand smoking initiation among individuals both in and out of college, as well as among individuals who engage primarily in social smoking [6]: college status (full-time student attending or planning to graduate from a 4-year program); months worked at a full-time paid job during the last calendar year (1-12); evenings out (three or more evenings out per week for fun/recreation). One additional measure-currently married or not - was chosen based on literature showing associations between young adult marital status and heavy smoking [8], cessation and initiation [9].

\section{Analysis}

Descriptive analyses were conducted using Stata version 13.1 [10]. Trend analyses were conducted using Joinpoint version 4.0.1 [11,12]. Multinomial logistic regression modeling of the time-invariant uptake measure and discrete-time survival models investigating the timing of young adult uptake were conducted using Mplus version 7.2 [13]. Survival models examined the non-proportional hazard odds of various forms of young adult smoking uptake occurring at each model age (19/20, 21/22, 23/24, 25/26) using maximum likelihood estimation, controlling for both time-invariant and time-varying characteristics (see Fig. 1). Individuals were considered to be rightcensored if no form of smoking uptake was reported by modal age 25/26. Attrition weights were calculated at each follow-up survey as the inverse of the probability of participation based on time-invariant characteristics measured at modal age 18 (gender, race/ethnicity, college plans, grade point average, number of parents in the home, region, religious commitment, cohort and the sampling weight accounting for over-sampling of substance users). Analyses accounted for the original complex high school senior sampling design by clustering on school. Missing data on time-invariant/-varying covariates were addressed by using full-information maximum-likelihood estimation in Mplus [13].

\section{RESULTS}

\section{Analytical sample}

A total of 73301 respondents were sampled for follow-up in the 30 class cohorts from 1976 to 2005. Of these, 42110 (57\%) participated at modal age 25/26. Limiting the sample further to those reporting no life-time smoking as a senior in high school yielded 13233 cases. An additional 2466 cases were removed due to missing data on variables necessary to code young adult smoking uptake; nine cases were removed due to missing gender data. The final analytical sample included 10758 individuals first surveyed as never-smoking high school seniors from 1976 to 2005 , with modal ages ranging from 18 to 25/26 years. Supporting information, Tables S1 and S2, provide weighted descriptive information on all covariates.

\section{Uptake prevalence}

Any young adult smoking uptake by modal age 25/26 was reported by $19.7 \%$ [ $95 \%$ confidence interval $(\mathrm{CI})=18.9$ $20.6 \%$ ] of respondents. Uptake to experimental smoking was reported by only $7.1 \%(95 \% \mathrm{CI}=6.6-7.6 \%)$, uptake to occasional but not regular smoking was reported by $6.5 \%(95 \% \mathrm{CI}=6.1-7.0 \%)$ and uptake to regular smoking was reported by $6.1 \%(95 \% \mathrm{CI}=5.7-6.6 \%)$. Figure 2 presents trends in (a) the prevalence of any young adult smoking uptake and (b) the percentage of high school seniors reporting no life-time cigarette smoking. 


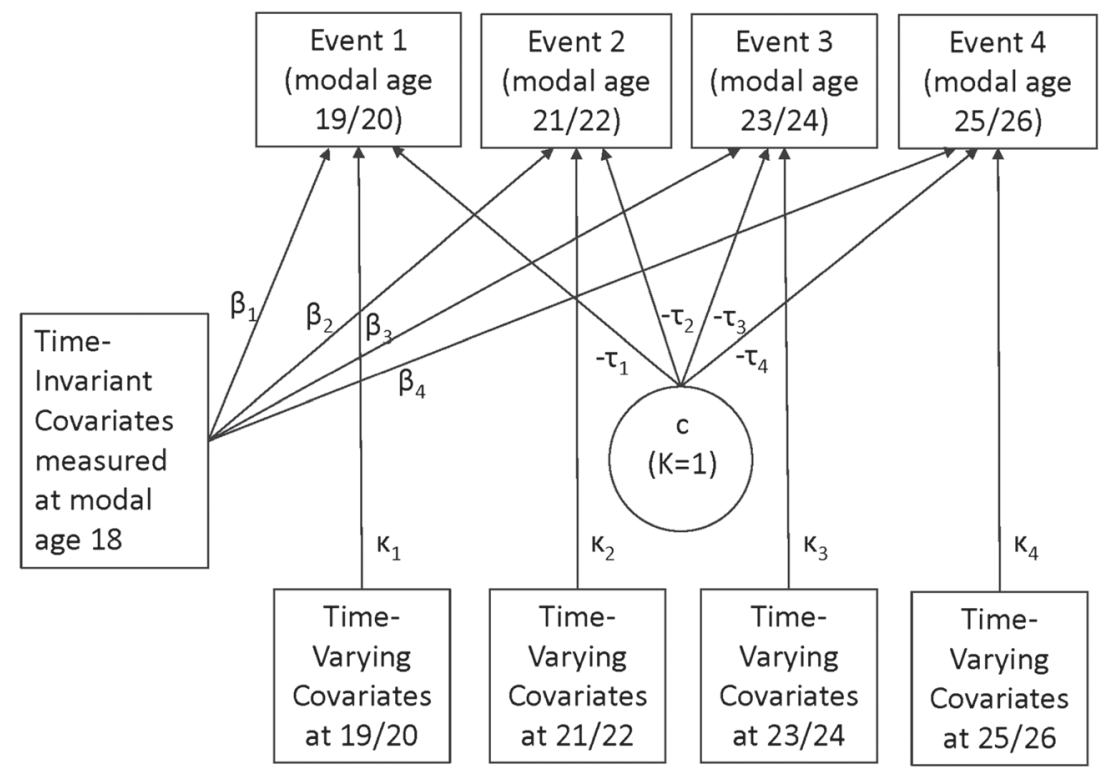

Notes: Data are right-censored if uptake not reported by modal age $25 / 26$. Both $\beta$ and $\kappa$ indicate logit estimates; $-\tau$ indicates the logit of the hazard probability of smoking uptake occurring by the time interval noted among those at risk in that time interval (i.e., among those for whom uptake has not previously occurred).

Figure I Discrete-time survival model approach used for examining young adult smoking uptake from modal age 19/20 to 25/26

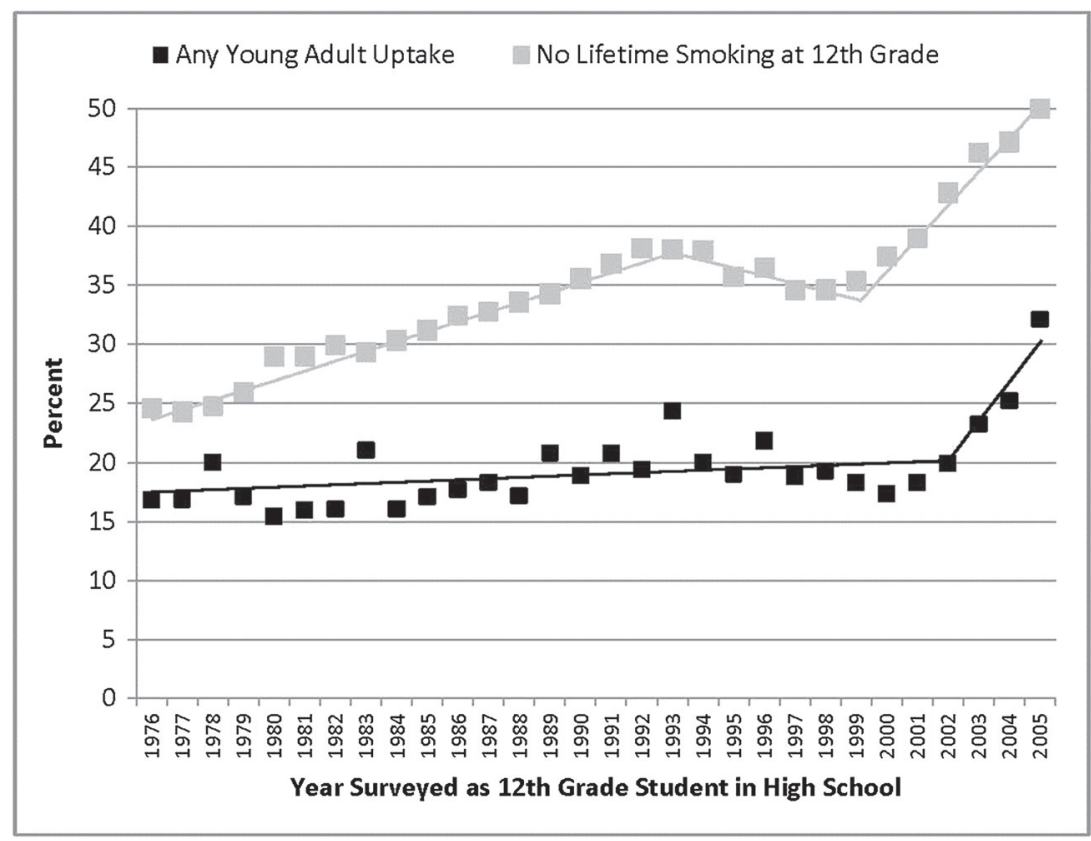

Notes: Any young adult uptake includes uptake to experimental only, occasional but not regular, and regular smoking between modal ages $19 / 20$ and $25 / 26$. From 1976-2002, slope estimate for any uptake 0.12 , SE 0.05 , $\mathrm{p}=.028$. From 2002-2005, slope estimate for any uptake $3.46, \mathrm{SE} 1.70, \mathrm{p}=.052$. The $\mathrm{x}$-axis refers to the baseline measurement year.

Figure 2 Trends in no life-time smoking by $12^{\text {th }}$ grade and the prevalence of any young adult smoking uptake to modal age 25/26

(Prevalence estimates for no life-time smoking among high school seniors obtained from analyses using all available 12th grade MTF study participants.) The percentage of high school seniors reporting no life-time smoking increased significantly over time; any young adult smoking uptake followed a similar trajectory, but with a slower rate of increase among 1976/1994 cohorts. Approximately $25 \%$ of seniors in the class of 1976 had never smoked, approximately $17 \%$ of whom took up smoking by age 25/26 (in 1983/1984). In contrast, approximately 50\% of seniors in the class of 2005 had never smoked, and approximately $32 \%$ of those took up smoking by age $25 / 26$ 


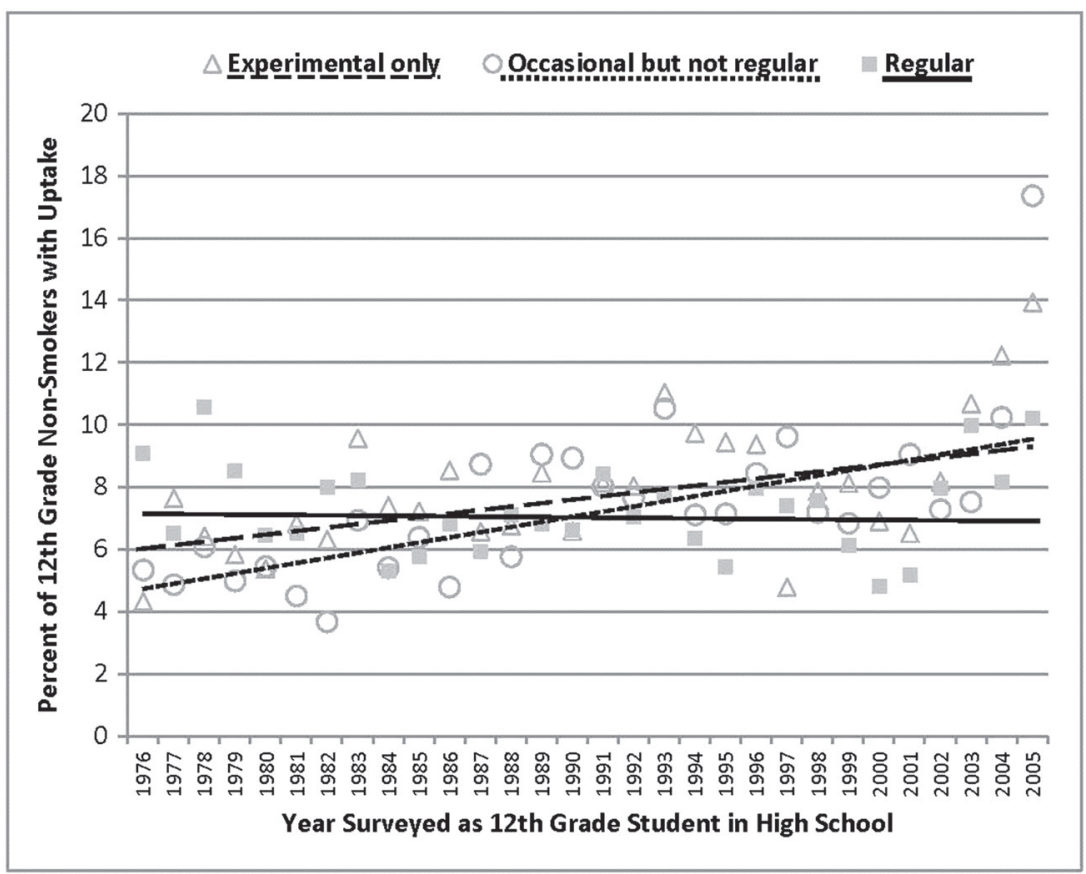

Notes: Forms of uptake measured between modal ages $19 / 20$ and $25 / 26$. Slope estimate for experimental uptake only $0.11, \mathrm{SE} 0.04, \mathrm{p}=0.005$. Slope estimate for uptake to occasional but not regular $0.17, \mathrm{SE} 0.03, \mathrm{p}=<0.001$. Slope estimate for regular uptake -0.02 , SE $0.03, \mathrm{p}=0.632$.

Figure 3 Trends in the prevalence of various forms of young adult smoking uptake to modal age 25/26

(in 2012/2013). Figure 3 presents trends over time in the prevalence of young adult smoking uptake in various forms. Significant increases over time were observed for uptake to both experimental and occasional smoking; no significant change over time was observed for uptake to regular smoking.

Multivariate multinomial logistic regression analysis results examining time-invariant characteristic associations with the relative risk of young adult smoking uptake (regardless of when uptake occurred) are shown in Table 2. Being male was associated with higher relative risk of regular uptake, but not experimental or occasional uptake. African Americans had lower relative risk than whites of experimental and occasional (but not regular) uptake. Hispanics had lower relative risk than whites of regular uptake. Respondents who definitely planned on attending college had a higher risk of occasional uptake. Higher parental education was associated with higher risk of experimental uptake, but lower risk of regular uptake. Alcohol use as a 12th grader was associated with increased risk of all uptake levels; marijuana use as a 12th grader was associated with higher risk of occasional and regular uptake. No significant regional associations were observed.

\section{Uptake timing}

Table 3 shows when respondents reported smoking uptake. As noted previously, $80 \%$ of respondents (8422) remained non-smokers. Of those who did report young adult smoking uptake, higher proportions generally reported first moving to various uptake levels at modal age 19/20, with decreasing proportions at later modal ages. One exception was uptake to occasional but not regular smoking, where approximately equal proportions reported first engaging in the behavior at modal ages 19/20 and 21/22.

Separate multivariate discrete-time survival analyses were run for each smoking uptake level including time-invariant/-varying characteristics. The analytical sample for each model included respondents who never reported smoking uptake $(n=8422)$, as well as respondents reporting the relevant uptake level. Hazard odds ratios reflect differences in the likelihood of uptake at specific modal ages between those never reporting uptake and those reporting the specified uptake level based on included time-invariant/-varying characteristics. Table 4 summarizes the results for key characteristics (see Supporting information, Tables S3-S6, for full model results).

\section{Time-invariant covariates}

Males were significantly less likely than females to report any, experimental or occasional uptake at modal age 19/20. In contrast, males were significantly more likely than females to report any and experimental uptake at modal age 23/24 and any and occasional uptake at modal age 25/26. African Americans were significantly less likely than whites to report all levels of uptake other than regular uptake at modal ages 19/20 and 21/22. No significant 
Table 2 Multivariate associations between time-invariant characteristics (at modal age 18) and the relative risk of young adult smoking uptake by modal age $25 / 26$.

\begin{tabular}{|c|c|c|c|c|c|c|c|c|c|}
\hline & \multicolumn{3}{|c|}{ Never versus experimental only } & \multicolumn{3}{|c|}{ Never versus occasional but not regular } & \multicolumn{3}{|c|}{ Never versus regular } \\
\hline & $A R R R$ & $(95 \% C I)$ & $P$ & $A R R R$ & $(95 \% C I)$ & $P$ & $A R R R$ & $(95 \% C I)$ & $P$ \\
\hline \multicolumn{10}{|c|}{ Gender $($ referent $=$ female $)$} \\
\hline Male & 1.08 & $(0.92-1.27)$ & 0.336 & 1.02 & $(0.87-1.20)$ & 0.793 & 1.21 & $(1.02-1.44)$ & 0.027 \\
\hline \multicolumn{10}{|c|}{ Race/ethnicity $($ referent $=$ white $)$} \\
\hline African American & 0.65 & $(0.46-0.92)$ & 0.016 & 0.56 & $(0.39-0.81)$ & 0.002 & 0.91 & $(0.67-1.23)$ & 0.549 \\
\hline Hispanic & 1.19 & $(0.86-1.66)$ & 0.300 & 0.87 & $(0.58-1.32)$ & 0.508 & 0.62 & $(0.38-0.99)$ & 0.045 \\
\hline Other & 0.88 & $(0.64-1.22)$ & 0.448 & 0.80 & $(0.58-1.12)$ & 0.196 & 0.94 & $(0.68-1.31)$ & 0.723 \\
\hline \multicolumn{10}{|c|}{ College plans ${ }^{\mathrm{a}}($ referent $=$ other $)$} \\
\hline Definitely & 1.19 & $(0.94-1.50)$ & 0.154 & 1.94 & $(1.51-2.48)$ & $<0.001$ & 0.92 & $(0.74-1.14)$ & 0.430 \\
\hline \multicolumn{10}{|c|}{ At least one parent with college education $($ referent $=$ no) } \\
\hline Yes & 1.28 & $(1.09-1.50)$ & 0.002 & 1.17 & $(0.99-1.38)$ & 0.069 & 0.82 & $(0.68-0.98)$ & 0.029 \\
\hline \multicolumn{10}{|c|}{ Past 12-month alcohol use (referent = none $)$} \\
\hline Any & 1.67 & $(1.41-1.98)$ & $<0.001$ & 1.86 & $(1.56-2.22)$ & $<0.001$ & 2.15 & $(1.75-2.64)$ & $<0.001$ \\
\hline \multicolumn{10}{|c|}{ Past 12-month marijuana use $($ referent $=$ none $)$} \\
\hline Any & 1.01 & $(0.77-1.33)$ & 0.948 & 1.36 & $(1.04-1.77)$ & 0.024 & 1.98 & $(1.58-2.48)$ & $<0.001$ \\
\hline \multicolumn{10}{|c|}{ Region $($ referent $=$ South $)$} \\
\hline Midwest & 1.22 & $(1.00-1.50)$ & 0.052 & 1.19 & $(0.97-1.46)$ & 0.092 & 1.07 & $(0.87-1.31)$ & 0.554 \\
\hline Northeast & 0.89 & $(0.70-1.12)$ & 0.301 & 1.01 & $(0.81-1.26)$ & 0.908 & 1.02 & $(0.80-1.29)$ & 0.872 \\
\hline West & 1.20 & $(0.95-1.52)$ & 0.134 & 1.11 & $(0.86-1.43)$ & 0.441 & 0.80 & $(0.62-1.03)$ & 0.088 \\
\hline Cohort $^{b}$ & 1.02 & (1.01-1.03) & $<0.001$ & 1.03 & $(1.02-1.04)$ & $<0.001$ & 1.02 & $(1.01-1.03)$ & 0.002 \\
\hline
\end{tabular}

Unweighted $n=10758$. ARRR = adjusted relative risk ratio; $\mathrm{CI}=$ confidence interval. Base category $=$ never report young adult smoking uptake. Models also included a control for number of years past high school for the first follow-up. ${ }^{a} \mathrm{~A}$ dichotomous measure indicating plans to probably or definitely graduate from a 4-year college program. ${ }^{\mathrm{b}}$ Indicator of the year in which the respondent participated in the 12th grade survey (1976-2005).

Table 3 Timing of various levels of young adult smoking uptake between modal ages 19/20 and 25/26.

\begin{tabular}{|c|c|c|c|c|c|c|c|c|}
\hline & \multicolumn{2}{|c|}{ Modal age 19/20 } & \multicolumn{2}{|c|}{ Modal age 21/22 } & \multicolumn{2}{|c|}{ Modal age 23/24 } & \multicolumn{2}{|c|}{ Modal age 25/26 } \\
\hline & $\%$ & $(S E)$ & $\%$ & $(S E)$ & $\%$ & $(S E)$ & $\%$ & $(S E)$ \\
\hline First smoking uptake $\mathrm{a}^{\mathrm{a}}(n=2336)$ & 44.3 & $(1.07)$ & 28.4 & $(0.98)$ & 16.4 & $(0.87)$ & 10.9 & $(0.77)$ \\
\hline Uptake to experimental smoking only $(n=839)$ & 34.2 & $(1.66)$ & 27.7 & $(1.63)$ & 20.2 & $(1.55)$ & 17.9 & $(1.57)$ \\
\hline Uptake to occasional but not regular $(n=783)$ & 30.5 & $(1.65)$ & 32.2 & $(1.72)$ & 23.9 & $(1.75)$ & 13.4 & (1.44) \\
\hline Uptake to regular $(n=714)$ & 37.0 & $(1.87)$ & 33.2 & $(1.86)$ & 18.1 & $(1.61)$ & 11.7 & $(1.34)$ \\
\hline
\end{tabular}

Data shown only for those respondents who reported young adult smoking uptake (a total of 8422 cases did not report any smoking uptake). $\mathrm{SE}=$ standard error. ${ }^{a}$ Regardless of if move to a higher level of smoking at a later point.

differences between African American and white respondents were observed thereafter. Respondents who reported past 12-month alcohol use as a senior in high school had significantly higher odds of all uptake levels at model ages $19 / 20$ and 21/22, and significantly higher odds of regular uptake to modal age 25/26. Past 12-month use of marijuana as a high school senior was associated significantly with increased odds of any uptake at modal ages $19 / 20$ and $25 / 26$, and with increased odds of regular uptake at model ages 19/20 and 21/22. A significant cohort association was observed with the timing of all levels of uptake for at least one modal age. The likelihood of any uptake increased significantly across cohorts for all modal ages. Significant increases in likelihood across cohorts were observed for experimental uptake at modal ages 23/24 and 25/26; for occasional uptake at all modal ages other than 19/20; and for regular uptake at modal age 19/20.

The observed significant differences in the likelihood of various uptake levels by cohort indicated significant changes over time in when respondents were taking up various levels of smoking. To enable visual comparisons of such change, baseline hazard probabilities were modeled for each level of uptake for the first and last five cohort groups (1976-1980 and 2001-2005) (see Fig. 4). Results clearly show 
Table 4 Summary of key covariates in multivariate discrete-time survival models examining the timing of young adult smoking uptake among high school seniors graduating from 1976 to 2005.

Modal age at which noted level of smoking uptake occurred

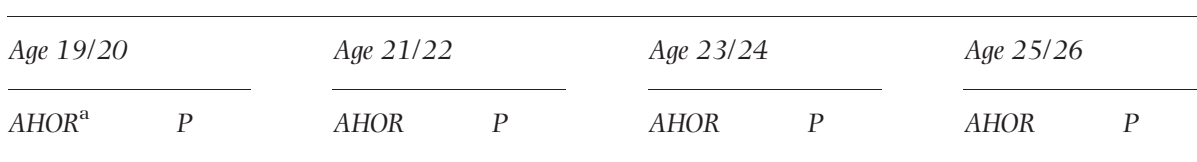

Time-invariant covariates measured at modal age 18

Male gender (referent $=$ female)

\begin{tabular}{|c|c|c|c|c|c|c|c|c|}
\hline Any uptake model & 0.85 & 0.015 & 0.89 & 0.185 & 1.40 & 0.008 & 1.44 & 0.027 \\
\hline Experimental model & 0.67 & 0.001 & 0.91 & 0.514 & 1.50 & 0.033 & 1.53 & 0.057 \\
\hline Occasional model & 0.64 & 0.001 & 0.91 & 0.457 & 1.18 & 0.369 & 1.74 & 0.026 \\
\hline Regular model & 1.24 & 0.096 & 0.88 & 0.383 & 0.98 & 0.908 & 1.59 & 0.081 \\
\hline \multicolumn{9}{|c|}{ frican American race/ethnicity (referent = white) } \\
\hline Any uptake model & 0.56 & $<0.001$ & 0.63 & 0.014 & 1.09 & 0.694 & 0.93 & 0.804 \\
\hline Experimental model & 0.58 & 0.049 & 0.55 & 0.039 & 0.77 & 0.537 & 0.78 & 0.594 \\
\hline Occasional model & 0.19 & $<0.001$ & 0.34 & 0.003 & 1.21 & 0.536 & 1.01 & 0.985 \\
\hline Regular model & 0.63 & 0.071 & 0.94 & 0.810 & 1.51 & 0.211 & 0.86 & 0.724 \\
\hline \multicolumn{9}{|c|}{ Iny past 12-month alcohol use (referent = none) } \\
\hline Any uptake model & 2.45 & $<0.001$ & 1.63 & $<0.001$ & 1.24 & 0.118 & 1.12 & 0.493 \\
\hline Experimental model & 2.39 & $<0.001$ & 1.66 & 0.001 & 1.46 & 0.069 & 0.93 & 0.713 \\
\hline Occasional model & 2.27 & $<0.001$ & 2.25 & $<0.001$ & 1.19 & 0.343 & 1.42 & 0.161 \\
\hline Regular model & 2.76 & $<0.001$ & 1.56 & 0.006 & 1.65 & 0.040 & 2.73 & 0.002 \\
\hline \multicolumn{9}{|c|}{ Iny past 12 -month marijuana use (referent $=$ none $)$} \\
\hline Any uptake model & 1.36 & 0.002 & 1.11 & 0.485 & 1.29 & 0.207 & 1.77 & 0.011 \\
\hline Experimental model & 0.99 & 0.962 & 0.69 & 0.170 & 1.08 & 0.831 & 1.37 & 0.308 \\
\hline Occasional model & 1.30 & 0.188 & 1.02 & 0.921 & 1.62 & 0.088 & 1.31 & 0.491 \\
\hline \multicolumn{9}{|l|}{ ohort $^{\mathrm{b}}$} \\
\hline Any uptake model & 1.02 & $<0.001$ & 1.02 & 0.001 & 1.02 & 0.015 & 1.04 & $<0.001$ \\
\hline Experimental model & 1.01 & 0.360 & 1.02 & 0.105 & 1.03 & 0.013 & 1.05 & 0.001 \\
\hline Occasional model & 1.01 & 0.096 & 1.03 & $<0.001$ & 1.04 & 0.001 & 1.05 & 0.002 \\
\hline Regular model & 1.03 & $<0.001$ & 1.00 & 0.626 & 1.02 & 0.158 & 1.01 & 0.628 \\
\hline
\end{tabular}

Time-varying covariates measured at each modal age

Currently attending college ${ }^{\mathrm{c}}($ referent $=$ no)

\begin{tabular}{|c|c|c|c|c|c|c|c|c|}
\hline \\
\hline Any uptake model & 1.23 & 0.012 & 1.31 & 0.014 & 0.99 & 0.962 & 0.80 & 0.333 \\
\hline Experimental model & 1.45 & 0.012 & 1.81 & 0.003 & 1.19 & 0.400 & 0.74 & 0.316 \\
\hline Occasional model & 1.70 & 0.002 & 2.11 & $<0.001$ & 0.63 & 0.040 & 1.09 & 0.793 \\
\hline Regular model & 0.69 & 0.019 & 0.69 & 0.026 & 0.95 & 0.846 & 0.10 & 0.009 \\
\hline \multicolumn{9}{|c|}{ Lurrently married $($ referent $=$ no) } \\
\hline Any uptake model & 0.72 & 0.073 & 0.56 & 0.001 & 0.34 & $<0.001$ & 0.66 & 0.032 \\
\hline Experimental model & 0.55 & 0.084 & 0.51 & 0.021 & 0.35 & 0.001 & 0.76 & 0.294 \\
\hline Occasional model & 0.44 & 0.072 & 0.57 & 0.071 & 0.28 & $<0.001$ & 0.31 & $<0.001$ \\
\hline Regular model & 1.12 & 0.661 & 0.89 & 0.602 & 0.38 & 0.001 & 0.41 & 0.005 \\
\hline \multicolumn{9}{|c|}{ Three or more evenings out per week (referent $=0-2$ ) } \\
\hline Any uptake model & 1.44 & $<0.001$ & 1.71 & $<0.001$ & 1.31 & 0.034 & 1.73 & 0.001 \\
\hline Experimental model & 1.00 & 0.977 & 1.37 & 0.029 & 1.38 & 0.085 & 1.88 & 0.005 \\
\hline Occasional model & 1.74 & $<0.001$ & 1.71 & $<0.001$ & 1.20 & 0.304 & 1.65 & 0.066 \\
\hline Regular model & 1.54 & 0.002 & 2.00 & $<0.001$ & 1.69 & 0.018 & 1.16 & 0.616 \\
\hline \multicolumn{9}{|c|}{ Months worked in the past year (continuous) } \\
\hline Any uptake model & 1.03 & 0.006 & 1.02 & 0.105 & 1.01 & 0.397 & 1.02 & 0.303 \\
\hline Experimental model & 1.02 & 0.183 & 1.01 & 0.545 & 1.00 & 0.990 & 1.02 & 0.547 \\
\hline Occasional model & 0.99 & 0.620 & 1.00 & 0.901 & 1.01 & 0.707 & 1.03 & 0.382 \\
\hline Regular model & 1.07 & $<0.001$ & 1.03 & 0.056 & 1.02 & 0.307 & 0.96 & 0.181 \\
\hline
\end{tabular}

Separate multivariate models were run for each of the following levels of young adult smoking uptake: any uptake $(n=10758)$, experimental only $(n=9261)$, up to occasional but not regular $(n=9205)$, up to regular $(n=9136)$. Each model simultaneously included time-invariant covariates (gender, race/ethnicity, college plans, parental education, past 12-month alcohol and marijuana use, region, cohort and a dichotomous indicator identifying if the respondent was first followed-up 1 or 2 years post-high school) and time-varying covariates (currently attending college, currently married, evenings out per week, number of months worked during the past calendar year). Full results for all models can be found in the Supporting information. ${ }^{\mathrm{a}} \mathrm{AHOR}=$ adjusted hazard odds ratio. ${ }^{b}$ Indicator of the year in which the respondent participated in the 12th grade survey (1976-2005), coded as 1-30. ${ }^{c}$ Full-time student either attending or with plans to graduate from a 4-year program. 


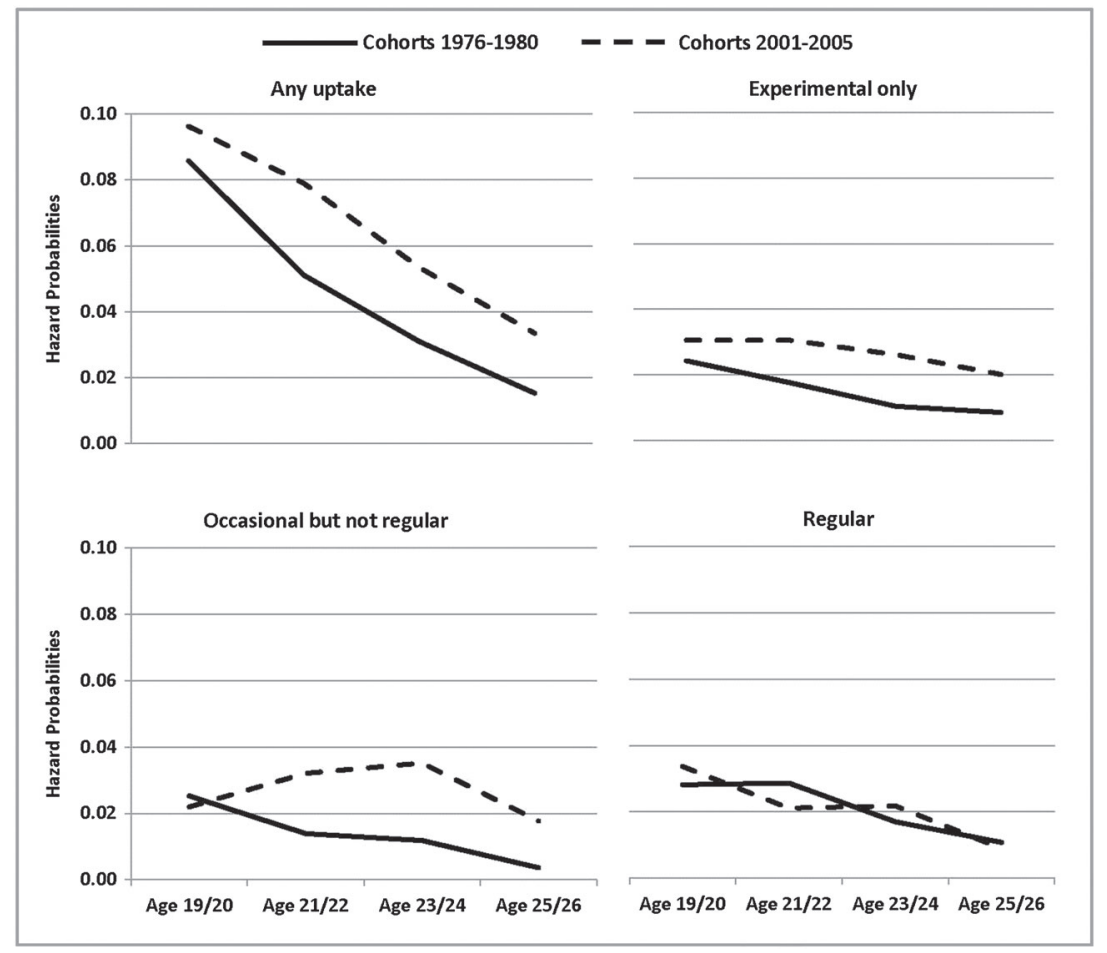

Notes: Unweighted sample sizes for 1976-1980 cohorts: 1,639 (any uptake); 1,434 (experimental); 1,426 (occasional); 1,469 (regular). Unweighted sample sizes for 2001-2005 cohorts: 1,730 (any uptake); 1,457 (experimental); 1,446 (occasional); 1,407 (regular).

Figure 4 Changes in the timing of young adult smoking uptake: baseline hazard probabilities of various levels of smoking uptake for cohorts 1976-1980 and 200I-2005

increased hazard probabilities for all forms of uptake other than regular smoking at modal ages 23/24 and $25 / 26$, as well as increased odds of any uptake and uptake to occasional smoking at modal age 21/22.

\section{Time-varying covariates}

Currently attending college significantly increased the likelihood of any/experimental/occasional uptake and decreased the likelihood of regular uptake at modal ages 19/20 and 21/22 (currently attending college also significantly decreased the likelihood of regular uptake at modal ages 25/26). Currently being married was associated with significantly lower odds of any uptake at all modal ages other than 19/20, and with most levels of uptake at modal ages 23/24 and 25/26 (excluding experimental uptake at modal age 25/26). Going out for fun/recreation on three or more evenings per week was associated with higher odds of any uptake at all modal ages, with higher odds of experimental uptake at modal ages 21/22 and 25/26, with occasional uptake at modal ages 19/20 and 21/22 and regular uptake at all modal ages other than 25/26. A higher number of months worked at a full-time job in the past year was associated with higher odds of any uptake, and uptake to regular smoking, at modal age 19/10.

\section{DISCUSSION}

Results indicate that the likelihood of any young adult smoking uptake by age 25/26 increased significantly between 1976 and 2005. The likelihood of uptake to experimental smoking only, and to occasional but not regular smoking, increased; the likelihood of regular smoking uptake remained stable. Overall, uptake remained most likely to occur at age 19/20, but the prevalence of late uptake at older ages increased over time. The US Office of Disease Prevention and Health Promotion has an objective of reducing adult smoking prevalence to $12 \%$ or less by 2020 [14]. Such reductions will, in part, be based on reduced adolescent smoking initiation, but efforts to reach this objective also will need to focus on young adults. Studies have shown an increasing trend in the likelihood of becoming a regular smoker in early adulthood [15], with evidence of higher young adult initiation rates among recent birth cohorts [16]. New York City recently reported its first increase in adult cigarette smoking in years [17]. The Monitoring the Future study has documented dramatic declines in US adolescent smoking in recent years: $62 \%$ of seniors in the class of 2013 had not initiated cigarette use, compared to only $24 \%$ in 1977 [18]. However, current study results indicate that for an increasing percentage of individuals, the uptake process is simply delayed until after adolescence. 
The lower rate of increase in young adult uptake (compared with the higher rate of increase in adolescent lifetime non-smoking) means that fewer individuals overall have taken up smoking. However, the increasing rate of young adult uptake calls for clear and concerted prevention efforts among this population.

The current study expands knowledge on young adult smoking uptake by reporting differential rates of change by uptake level. Prevalence comparisons for cohorts graduating high school in 1976-80 with those graduating in 2001-05 showed virtually no difference with regard to regular uptake. To the extent that regular smoking may have more attendant health consequences and social costs than experimental or occasional smoking, the relative stability of young adult regular smoking uptake (and the increasing rate of life-time adolescent non-smoking) is good news from a public health standpoint. However, prevalence essentially doubled for experimental (from 6 versus 10\%) and occasional uptake (from 5 versus $10 \%$ ). It is becoming increasingly likely that some individuals who reach the age of 18 as non-smokers will become involved with some level of cigarette smoking (and its attendant health consequences and costs) as young adults. These results support the literature's call for increased knowledge of the phenomena of social or occasional smoking [6]. The current analysis defined occasional smoking uptake as moving from no life-time smoking to smoking up to occasionally in the past 12 months, and smoking less than one cigarette per day in the past 30 days. This classification can still encompass significant smoking activity; research is conclusive that even low levels of tobacco smoke exposure can lead to serious health consequences [19]. It is also possible, indeed likely, that some portion of those who were occasional smokers by age $25 / 26$ will go on to become regular smokers. The current study found fewer than half (44\%) of those reporting any young adult smoking uptake (and fewer than one-third of those reporting occasional uptake) had done so by age 19/20. Prevention efforts are clearly needed among the young adult population to modal age 25/26. Increased prevention focus on individuals in their mid$20 \mathrm{~s}$ is especially relevant, given that the probability of reporting late uptake at modal ages 23/24 and 25/26 has increased significantly with recent cohorts.

Previous studies examining socio-demographic associations with young adult smoking uptake have shown mixed results. For example, some studies have found no significant gender differences [4,20,21], while others have found that males are significantly more at risk $[6,15,22,23]$. Similar conflicting findings have been reported for race/ethnicity [6,21,22,24-26]. Prior research has not been able to examine how time-invariant/-varying characteristic associations vary with level or timing of uptake. The current study indicates that associations vary depending on what level of uptake is being considered and when such uptake occurs. Prevention efforts, including denormalization campaigns, may have the best potential to succeed if observed differences in associations are recognized and incorporated, with messages tailored to the desired target audience. For example, campaigns focusing on experimental or occasional smoking should consider especially targeting college students and females, while campaigns focusing on regular smoking should consider a focus on individuals moving directly to the work-force after high school.

Alcohol use as a senior in high school was associated strongly with uptake at all uptake levels. In past research, alcohol use during high school has been shown to be a significant predictor of later smoking initiation [27], possibly working through potential peer influences and social environments in which drinking and smoking co-occur. This possibility was supported by the finding that frequently going out for evenings of fun/recreation was associated with increased risk of at least one form of smoking uptake at each modal age. Prior research has shown that young adults are particularly receptive to cigarette marketing efforts [24], and that the tobacco industry has focused historically on young adults as a key demographic group that could be reached especially through social situations such as parties, concerts and clubs [25,28-31].

\section{Limitations}

The current study is subject to limitations. Findings may not generalize to individuals who drop out prior to their senior year in high school; lower educational attainment is associated with higher smoking initiation risk $[20,21,25,32,33]$. The degree to which findings may generalize to individuals for whom data on uptake were missing (19\% of the sample) is also unknown. This study focused only on late cigarette smoking uptake. Young adults initiate tobacco use with many types of tobacco products [34]. Data are all based on self-reports, which have been found to be reasonably reliable and valid under appropriate conditions, which the MTF study has striven to provide [35-38]. These limitations notwithstanding, the current study contributes significantly to the available knowledge on young adult smoking uptake.

\section{Conclusions}

Economic and social costs associated with cigarette smoking currently approach $\$ 300$ billion annually [39]. While US adolescent cigarette use has decreased dramatically [37], the current analysis shows that the likelihood of young adult smoking uptake has increased over time and has become more likely to occur later in young adulthood. While counter-industry marketing/denormalization campaigns, smoke-free policies and cigarette tax increases 
have been shown to reduce young adult initiation [6], continued development and implementation of effective prevention and cessation messages targeting young adults are clearly needed.

\section{Declaration of interests}

Monitoring the Future is supported by the National Institute on Drug Abuse (DA001411 and DA016575), which has imposed no contractual constraints on publishing. The authors have no connection with the tobacco, alcohol, pharmaceutical or gaming industries or any entity funded substantially by one of these organizations.

\section{Acknowledgements}

Monitoring the Future is supported by the National Institute on Drug Abuse (grants DA001411 and DA016575). The views expressed in this paper are those of the authors and do not necessarily reflect the views of the funders.

\section{References}

1. World Health Organization. WHO Framework Convention on Tobacco Control. World Health Organization: Geneva, Switzerland; 2003.

2. Pierce J. P., White V. M., Emery S. L. What public health strategies are needed to reduce smoking initiation? Tob Control 2012; 21: 258-64.

3. Institute of Medicine (IOM), National Research Council (NRC). Investing in the Health and Well-Being of Young Adults. The National Academies Press: Washington, DC; 2014.

4. Hammond D. Smoking behavior among young adults: beyond youth prevention. Tob Control 2005; 14: 181-5.

5. US Department of Health and Human Services. The Health Consequences of Smoking - 50 Years of Progress. A report of the Surgeon General. US Department of Health and Human Services, Centers for Disease Control and Prevention, National Center for Chronic Disease Prevention and Health Promotion, Office on Smoking and Health: Atlanta, GA; 2014.

6. Freedman K. S., Nelson N. M., Feldman L. L. Smoking initiation among young adults in the United States and Canada, 1998-2010: a systematic review. Prev Chronic Dis 2012; 9: 10037.

7. Johnston L. D., O'Malley P. M., Bachman J. G., Schulenberg J. E., Miech R. A. Monitoring the Future National Survey Results on Drug Use, 1975-2013, vol. II. College Students and Adults Ages 19-55. Institute for Social Research, University of Michigan: Ann Arbor, MI; 2014.

8. Bachman J. G., O'Malley P. M., Schulenberg J. E., Johnston L. D., Bryant A. L., Merline A. C. The Decline of Substance Use in Young Adulthood: Changes in Social Activities, Roles, and Beliefs. Lawrence Erlbaum Associates: Mahwah, NJ; 2002.

9. Thompson A. B. Smoking initiation after marriage and parenting among black and white women. Am J Health Behav 2014; 38: 577-85.

10. StataCorp. Stata Statistical Software: Release 13. StataCorp LP: College Station, TX; 2013.

11. National Cancer Institute (NCI). Joinpoint Regression Program, version 4.0.1. Statistical Research and Applications Branch, National Cancer Institute: Bethesda, MD; 2013.
12. Kim H. J., Fay M. P., Feuer E. J., Midthune D. N. Permutation tests for Joinpoint regression with applications to cancer rates. Stat Med 2000; 19: 335-51 (correction: 2001; 20: 655).

13. Muthén L. K., Muthén B. O. Mplus User's Guide, 7th edn. Los Angeles, CA: Muthén \& Muthén; 1998-2012.

14. US Office of Disease Prevention and Health Promotion. Healthy People 2020 Leading Health Indicators: Progress Update. US Department of Health and Human Services, Office of Disease Prevention and Health Promotion; March 2014. Available at: https://www.healthypeople.gov/sites/default/files/LHI-ProgressReport-ExecSum_0.pdf (accessed 26 November 2014). Archived at: http://www.webcitation. org/6UNGUwHqN on 26 November 2014.

15. Lantz P. M. Smoking on the rise among young adults: implications for research and policy. Tob Control 2003; 12: i60e70.

16. Wagenknecht L. E., Craven T. E., Preisser J. S., Manolio T. A., Winders S., Hulley S. B. Ten-year trends in cigarette smoking among young adults, 1986-1996: the CARDIA study. Ann Epidemiol 1998; 8: 301-7.

17. New York City Department of Health and Mental Hygiene. New Health Department data show increase in adult smoking rate. September 15, 2014. Available at: http://www.nyc.gov/html/doh/html/pr2014/pr035-14. shtml (accessed 6 February 2015). Archived at: http:// www.webcitation.org/6W8yekqzq on 6 February 2015.

18. Johnston L. D., O'Malley P. M., Bachman J. G., Schulenberg J. E., Miech R. A. Monitoring the Future National Survey Results on Drug Use, 1975-2013, vol. I. Secondary School Students. Institute for Social Research, University of Michigan: Ann Arbor; 2014.

19. Office of Surgeon General. How Tobacco Smoke Causes Disease: the Biology and Behavioral Basis for SmokingAttributable Disease. A Report of the Surgeon General. Department of Health and Human Services, Public Health Service, Office of the Surgeon General: Rockville, MD; 2010.

20. O’Loughlin J. L., Dugas E. N., O'Loughlin E. K., Karp I., Sylvestre M.-P. Incidence and determinants of cigarette smoking initiation in young adults. J Adolesc Health 2014; 54: 26-32.

21. Ellickson P. L., McGuigan K. A., Klein D. J. Predictors of lateonset smoking and cessation over 10 years. J Adolesc Health 2001; 29: 101e8.

22. Bernat D. H., Klein E. G., Forster J. L. Smoking initiation during young adulthood: a longitudinal study of a populationbased cohort. J Adolesc Health 2012; 51: 497e502.

23. Tjora T., Hetland J., Aarø L. E., Wold B., Øverland S. Late-onset smokers: how many, and associations with health behaviours and socioeconomic status. Scand J Public Health 2012; 40: $537 \mathrm{e} 43$.

24. Biener L., Albers A. B. Young adults: vulnerable new targets of tobacco marketing. Am J Public Health 2004; 94: 326-330.

25. Backinger C. L., Fagan P., Mathews E., Grana R. Adolescent and young adult tobacco prevention and cessation: current status and future directions. Tob Control 2003; 12: iv46-53.

26. Flint A. J., Novotny T. E. Trends in black/white differences in current smoking among 18- to 24-year-olds in the United States, 1983-1993. Am J Prev Med 1998; 14: 19-24.

27. Tercyak K. P., Rodriguez D., Audrain-McGovern J. High school seniors' smoking initiation and progression 1 year after graduation. Am J Public Health 2007; 97: 1397e8.

28. Business Information Analysis Corporation. RJR young adult motivational research. R. J. Reynolds Tobacco Company; 10 Jan 1985. Bates no. 502780379-0424. 
Available at: http://www.legacy.library.ucsf.edu/tid/xng78d00 (accessed 14 October 2014). Archived at: http://www. webcitation.org/6UNHlwb4V on 26 November 2014.

29. Katz S. K., Lavack A. M. Tobacco related bar promotions: insights from tobacco industry documents. Tob Control 2002; 11: i92-101.

30. Ling P. M., Glantz S. A. Why and how the tobacco industry sells cigarettes to young adults: evidence from industry documents. Am J Public Health 2002; 92: 908-916.

31. Sepe E., Glantz S. A. Bar and club promotions in the alternative press: targeting young adults. Am J Public Health 2002; 92: $75-78$.

32. Bachman J. G., O'Malley P. M., Johnston J. J. Youth in Transition, vol. VI. Adolescence to Adulthood - a Study of Change and Stability in the Lives of Young Men. Institute for Social Research, University of Michigan: Ann Arbor; 1978.

33. Bachman J. G., O'Malley P. M., Schulenberg J. E., Johnston L. D., Freedman-Doan P., Messersmith E. E. The Education-Drug Use Connection: How Successes and Failures in School Relate to Adolescent Smoking, Drinking, Drug Use, and Delinquency. Lawrence Erlbaum Associates: New York, NY; 2008.

34. Rath J. M., Villanti A. C., Abrams D. B., Vallone D. M. Patterns of tobacco use and dual use in US young adults: the missing link between youth prevention and adult cessation. J Environ Public Health 2012; 2012: 679134.

35. Brener N. D., Billy J. O. G., Grady W. R. Assessment of factors affecting the validity of self-reported health-risk behavior among adolescents: evidence from the scientific literature. J Adolesc Health 2003; 33: 436-57.

36. Johnston L. D., O'Malley P. M. Issues of validity and population coverage in student surveys of drug use. In: Rouse B. A., Kozel N. J., Richards L. G., editors. Self-report Methods of Estimating Drug Use: Meeting Current Challenges to Validity. NIDA Research Monograph no. 57. National Institute on Drug Abuse: Washington, DC; 1985.

37. Johnston L. D., O’Malley P. M., Bachman J. G., Schulenberg J. E., Miech R. A. Monitoring the Future National Survey Results on Drug Use, 1975-2013, vol. I. Secondary School Students. Institute for Social Research, University of Michigan: Ann Arbor; 2014.

38. O'Malley P. M., Bachman J. G., Johnston L. D. Reliability and consistency of self-reports of drug use. Int J Addict 1983; 18: 805-24.
39. Centers for Disease Control and Prevention. Best Practices for Comprehensive Tobacco Control Programs-2014. US Department of Health and Human Services, Centers for Disease Control and Prevention, National Center for Chronic Disease Prevention and Health Promotion, Office on Smoking and Health: Atlanta, Georgia; 2014.

\section{Supporting Information}

Additional supporting information may be found in the online version of this article at the publisher's web site:

Appendix S1 STROBE Statement Checklist of Items That Should be Included in Reports of Cohort Studies.

Appendix S2 Sample Flow Diagram.

Table S1 Weighted Descriptives of Time-Invariant Covariates Measured at Modal Age 18 (Total Sample N=10,758). Table S2 Weighted Descriptives of Time-Varying Covariates (Total Sample N=10,758).

Table S3 Multivariate Discrete-Time Survival Models Examining the Timing of Any Young Adult Smoking Uptake among High School Seniors Graduating from 1976-2005.

Table S4 Multivariate Discrete-Time Survival Models Examining the Timing of Uptake to Experimental Smoking Only among High School Seniors Graduating from 1976-2005.

Table S5 Multivariate Discrete-Time Survival Models Examining the Timing of Uptake to Occasional but Not Regular Smoking among High School Seniors Graduating from 1976-2005.

Table S6 Multivariate Discrete-Time Survival Models Examining the Timing of Uptake to Regular Smoking among High School Seniors Graduating from 1976-2005. 